\title{
Morphological localisation of sulfonylurea receptor 1 in endocrine cells of human, mouse and rat pancreas
}

\author{
Y. Guiot • M. Stevens • I. Marhfour • P. Stiernet • \\ M. Mikhailov • S. J. H. Ashcroft • J. Rahier • \\ J.-C. Henquin • C. Sempoux
}

Received: 15 March 2007 / Accepted: 14 May 2007 / Published online: 26 June 2007

(C) Springer-Verlag 2007

\begin{abstract}
Aims/hypothesis Sulfonylurea receptor 1 (SUR1) is the regulatory subunit of ATP-sensitive $\mathrm{K}$ channels in beta cells. Morphological methods (immunohistochemistry and sulfonylurea binding) were used to establish the cellular and subcellular location of SUR1 in human and rodent islets.

Results In the human, mouse and rat pancreas, all endocrine cells of the islets were immunolabelled with an antiSUR1 antibody, whereas tissues containing SUR2 were consistently negative, as were those from Surl (also known as $A b c c 8)^{-/-}$mice. In beta cells of the three species, the plasma membrane was distinctly stained, but SUR1 was mainly present over the cytoplasm, with an intensity that varied between cells. Electron microscopy showed that SUR1 was immunolocalised in insulin, glucagon and somatostatin granules. In rat beta cells degranulated by in
\end{abstract}

\footnotetext{
Y. Guiot $(\triangle) \cdot$ M. Stevens $\cdot$ I. Marhfour $\cdot$ J. Rahier $\cdot$ C. Sempoux Department of Pathology, Faculty of Medicine,

University of Louvain,

B-1200 Brussels, Belgium

e-mail: guiot@anps.ucl.ac.be

P. Stiernet $\cdot$ J.-C. Henquin

Endocrinology Unit and Metabolism, Faculty of Medicine,

University of Louvain,

UCL5530, Brussels, Belgium

M. Mikhailov

Physiology Laboratory, University of Oxford,

Oxford, UK

S. J. H. Ashcroft

Oxford Centre for Diabetes, Endocrinology and Metabolism,

University of Oxford,

Oxford, UK
}

vivo treatment with glibenclamide (known as glyburide in the USA and Canada), the insulin and SUR1 staining intensity was similarly decreased by $\sim 45 \%$, whereas SUR 1 staining was not changed in non-beta cells. In all islet cells, binding of glibenclamide labelled with fluorescent dipyrromethane boron difluoride (BODIPY-FL) was punctate over the cytoplasm, compatible with the labelling of endocrine granules. A faint labelling persisted in $\mathrm{Surl}^{-/}$mice, but it was not different from that obtained with BODIPY-FL alone used as negative control.

Conclusions/interpretation Our study immunolocalised SUR1 in alpha, beta and delta cells of human, mouse and rat islets, and for the first time visualised it in the plasma membrane. We also show that SUR1 is abundant in endocrine granules, where its function remains to be established. No specific sulfonylurea-binding sites other than SUR1 are identified in islet cells by the glibenclamideBODIPY-FL technique.

Keywords Electron microscopy · Endocrine granule · Glibenclamide · Immunohistochemistry $\cdot$ Insulin secretion · Islets · SUR1 · SUR1 knockout mice

$\begin{array}{ll}\text { Abbreviations } & \\ \text { BODIPY } & \text { dipyrromethane boron difluoride } \\ \text { DAB } & 3,3^{\prime} \text {-diaminobenzidine } \\ \text { gSUR } & \text { granular sulfonylurea receptor } \\ \text { Hx } & \text { haematoxylin counterstaining } \\ \mathrm{K}_{\text {ATP }} \text { channel } & \text { ATP-sensitive K channel } \\ \text { SOD } & \text { specific optical density } \\ \text { SUR1 } & \text { sulfonylurea receptor } 1 \\ \text { Sur1 }^{--} & \text {SUR1 knockout mice }\end{array}$




\section{Introduction}

The beta cell ATP-sensitive $\mathrm{K}\left(\mathrm{K}_{\mathrm{ATP}}\right)$ channel is composed of four subunits of Kir6.2, an inwardly rectifying $\mathrm{K}^{+}$ channel and four subunits of sulfonylurea receptor 1 (SUR1), acting as the channel regulator [1-4]. $\mathrm{K}_{\text {ATP }}$ channels play a key role in insulin secretion by linking cellular metabolism and electrical activity in beta cells [58]. In response to an increase in blood glucose concentration, beta cell metabolism accelerates, which results in cytosolic nucleotide changes that lead to $\mathrm{K}_{\mathrm{ATP}}$ channel closure. The beta cell membrane depolarisation that follows opens voltage-dependent $\mathrm{Ca}^{2+}$ channels leading to $\mathrm{Ca}^{2+}$ influx. The resulting rise in cytosolic $\mathrm{Ca}^{2+}$ concentration is the triggering signal for the exocytosis of insulin-containing granules. Although the full secretory response to glucose also involves amplification of the action of $\mathrm{Ca}^{2+}[7,9,10]$, the $\mathrm{K}_{\mathrm{ATP}}$ channel-dependent rise of cytosolic $\mathrm{Ca}^{2+}$ is essential [11]. Beta cell $\mathrm{K}_{\mathrm{ATP}}$ channels are also the target of pharmacological agents [12], among which sulfonylureas and glinides are of major clinical importance. These hypoglycaemic drugs induce $\mathrm{K}_{\mathrm{ATP}}$ channel closure by binding to high-affinity sites in SUR1 [13, 14], thereby mimicking the effect of glucose on the production of a triggering signal for insulin secretion.

Electrophysiological studies have functionally localised $\mathrm{K}_{\text {ATP }}$ channels, hence SUR1, to the plasma membrane of beta cells, but no morphological study has yet been able to visualise it at that level. In contrast, two immunohistochemical studies in rodents have shown that SUR1 is abundantly distributed over the beta cell cytoplasm [15, 16]. Moreover, studies using ${ }^{3} \mathrm{H}$-labelled glibenclamide (known as glyburide in the USA and Canada) have shown that, unlike other sulfonylureas, glibenclamide is taken up by beta cells [17] and binds to an intracellular protein that is much more abundant (more than tenfold) than in the plasma membrane [18]. These conclusions were extended recently by monitoring the binding of glibenclamide labelled with fluorescent dipyrromethane boron difluoride (BODIPY-FL) to islet cells [16, 19], a technique that is, however, complicated by a significant degree of non-specific binding due to the lipophilicity of the probe [20].

The intracellular glibenclamide-binding sites or SUR1 itself have variably been located to insulin granules [16, 21, $22]$, the nuclear membrane [23] or vesicles of an unknown nature [24]. In addition to its intracellular localisation, the nature of the binding protein is also contentious. ${ }^{3} \mathrm{H}$ labelled sulfonylureas have been reported to bind to a $65 \mathrm{kDa}$ protein [25], distinct from the native SUR1 protein $(140 \mathrm{kDa})$, and subsequently localised to the granule fraction from normal mouse islets [26]. This protein, named granular SUR (gSUR) protein, was proposed to mediate an augmentation of insulin release [26, 27].
The localisation of SUR1 in non-beta cells of the islet is also controversial. Functional evidence indicates that SUR1 and Kir6.2 are expressed [28] and form $\mathrm{K}_{\text {ATP }}$ channels [29] in rodent alpha cells, but one study using glibenclamideBODIPY failed to identify SUR1 in mouse glucagon cells [19]. This negative result conflicts with the immunolocalisation of SUR1 in the cytoplasm of both beta and non-beta cells of rat islets [15].

These divergent observations probably result from the application to the pancreas of rodents of different techniques of tissue isolation and preparation and distinct procedures of visualisation. They also leave open the question of SUR1 location in human islets. The aim of the present study was to establish the cellular and subcellular location of SUR1 in the human and rodent endocrine pancreas. We first strictly assessed the histochemical reliability of an antibody directed against SUR1 [4] before searching for the presence of the protein in different islet cell types of three species (human, mouse and rat). Electron microscopy and pharmacological manipulation of the insulin content of the islets were then used to identify the subcellular location of SUR1. Immunohistochemical data were compared with those obtained by the classic glibenclamide-BODIPY binding technique in normal islet cell clusters.

\section{Materials and methods}

The study was approved by the ethics committee of the University of Louvain and conducted in accordance with the guidelines issued by the National Belgian Animal Care Committee.

Tissues Human pancreases were obtained from organ donors who had died from a pathology not known to affect the endocrine pancreas. Control C57BL/6 mice (local colony) and Surl (also known as $A b c c 8)^{-/}$mice [30] originally provided by J. Bryan (Baylor College of Medicine, Houston, TX, USA) were bred in Brussels. Wistar rats were obtained from a local colony. In one series of experiments, test rats received five i.p. injections of $2 \mathrm{mg} / \mathrm{kg}$ glibenclamide at $12 \mathrm{~h}$ intervals [31], while controls were injected with saline.

Tissue processing for microscopy For conventional microscopy, human and rodent tissues were fixed in Bouin Allen's fluid solution for $24 \mathrm{~h}$ and routinely embedded in paraffin. For electron microscopy, rats and mice were anaesthetised before being perfused with $4 \%$ (wt/vol.) paraformaldehyde buffered at $\mathrm{pH} 7.4$ and supplemented with $1 \%$ (wt/vol.) $\mathrm{CaCl}_{2}$. Thereafter the pancreas was immersed in the same fixative for $4 \mathrm{~h}$. Embedding with an epoxy medium (Fluka, Buchs, Switzerland) 
or with an acrylic resin (London Resin Company, Theale, UK) followed the manufacturer's recommendations.

Conventional microscopy The anti-SUR1 antibody, produced by two of us, was obtained by immunisation of rabbits with the E617-N987 amino acid sequence of SUR1, corresponding to the nucleotide-binding domain 1 [4]. Fivemicron thick sections were incubated overnight at $4^{\circ} \mathrm{C}$ with the antibody at dilutions of $1 / 300$ for rat, $1 / 600$ for mouse and at both dilutions for human tissues. The sections were then incubated with EnVision peroxidase directed to rabbit antibodies (Dako, Carpinteria, CA, USA) and finally with 3,3'-diaminobenzidine (DAB) (Fluka). After washing, some of the immunostained slides were haematoxylin counterstained $(\mathrm{Hx})$ to facilitate recognition of histological structures, but others were not.

Consecutive sections were used to identify the cells containing SUR1. Beta cells were labelled by incubation with a monoclonal anti-insulin antibody (human and rat 1 / 7,000; mouse 1/25,000; Chemicon International, Temecula, CA, USA), with detection by EnVision peroxidase and $\mathrm{DAB}$ revelation. Alpha and delta cells were stained using a cocktail of polyclonal antibodies against somatostatin (human and mouse 1/6,000; rat 1/3,000; gift from W. Gepts, Free University, Brussels, Belgium) and glucagon (all species 1/1,000; Novocastra Laboratories, Newcastle, UK). Both antibodies were detected simultaneously by an alkaline phosphatase detection system revealed by a naphthol Fast Red substrate.

In other series, insulin and glucagon cells were identified by immunofluorescence using the above antibodies at a 10 times higher concentration and combined with anti-mouse and anti-rabbit antibodies labelled with Texas Red and fluorescein, respectively (Dako).

Electron microscopy After a 15 min pretreatment with $50 \mu \mathrm{mol} / 1$ lysine, ultrathin sections were incubated with the anti-insulin antibody (rat pancreas, 1/50; Chemicon) and a biotinylated anti-mouse $\operatorname{IgG}(1 / 150$; Dako) or with the antiSUR1 antibody (1/100 and $1 / 400$ for rat and mouse pancreas, respectively) and a biotinylated anti-rabbit IgG (1/200; Chemicon). Finally, all sections were incubated with gold-labelled streptavidin particles $(1 / 20,10 \mathrm{~nm}$ particles; Aurion, Wageningen, the Netherlands). After rinses, sections were post-fixed with $2.5 \%$ (wt/vol.) glutaraldehyde for $5 \mathrm{~min}$ and counterstained. They were then examined on a Zeiss 109 transmission electron microscope (Zeiss, Oberkochen, Germany).

Immunohistochemical controls The best signal-to-noise ratio in SUR1 immunodetection was obtained without any antigen retrieval method, which reduces the risk of antibody cross-reaction with related proteins. Specificity of immu- nohistochemical techniques was assessed by the absence of labelling when the primary antibody was omitted or when an irrelevant polyclonal antibody (anti-fluorescein isothiocyanate; Dako) was used. Cross-reactions between antibodies were excluded by comparing stainings after simple and double immunodetection. The anti-SUR1 antibody has previously been characterised by western blotting [4]. Its histochemical specificity was assessed on slices of mouse or rat tissues known to contain SUR1 or not.

Islet cell preparation and glibenclamide binding Islet cell clusters from control and Sur1 $1^{-1}$ mice were obtained as previously described [32]. After 2 days of culture, clusters were incubated for $2 \mathrm{~h}$ at room temperature in standard Krebs' medium buffered with HEPES [32] and supplemented with either $10 \mathrm{nmol} / 1$ glibenclamide-BODIPY-FL (green fluorescence) or the fluorophore not coupled to glibenclamide, i.e. BODIPY-FL dye $(10 \mathrm{nmol} / \mathrm{l}$; Molecular Probes, Eugene, OR, USA). The clusters were then washed and directly imaged with an AxioImager Z1 Motorised Microscope combined with an ApoTome system and a highsensitivity camera (AxioCam HRm; Zeiss). In one series of experiments, intact islets from control mice were cultured overnight with $10 \mu \mathrm{mol} / 1$ glibenclamide and $2 \mu \mathrm{mol} / 1$ clonidine or with $2 \mu \mathrm{mol} / \mathrm{l}$ clonidine alone before being processed for light microscopy and immunostaining of SUR1.

Quantification SUR1 and insulin beta cell contents in rat islets were quantified by measuring the specific optical density (SOD) [31] of the DAB immunostaining with an image analyser KS-400 (Zeiss). All sections used for these quantifications were processed simultaneously. Results are given as means $\pm \mathrm{SD}$, and the statistical significance of the differences was assessed by Student's $t$ test. Pearson's test was used to assess the statistical significance of the correlation between insulin and SUR1 immunolabelling intensities in beta cells. Subcellular location of SUR1 was quantified with a Videoplan MOP-3 (Zeiss) on microphotographs of islet cells examined by electron microscopy. First, the number of immunogold particles was determined over and outside the insulin granule area, and expressed as a density (number of particles per surface unit), to assess the extent of granule labelling. Second, the number of insulin and SUR1 immunogold particles per insulin granule was also computed in well-granulated (control) and degranulated (by glibenclamide treatment) beta cells.

\section{Results}

Specificity of the anti-SUR1 antibody A positive immunoreaction was detected in cells of the dentate gyrus and in the 
pyramidal cell layers of the mouse hippocampus, two regions known to produce SUR1 abundantly [6, 33, 34] (Fig. 1a). Some tissues are known not to produce SUR1 but to contain SUR2 isoforms. Cardiomyocytes (SUR2A) (Fig. 1b) and vascular smooth muscle of the pancreas (SUR2B) (Fig. 1c, arrow) were not labelled by our antiSUR1 antibody. Similar results were obtained with rat tissues (not shown). In contrast, SUR1 staining was heavily positive in the islets (Fig. 1c). Besides islets, nerve fibres and nerve plexus scattered in the pancreatic parenchyma were also labelled by the SUR1 antibody in both humans (Fig. 1d) and rodents (not shown). Most importantly, in Surl ${ }^{-/}$mice no SUR1 labelling was observed in the hippocampus area (Fig. 1e) or any other tissue, such as the pancreas (Fig. 1f). Insulin- (red) and somatostatin- (green) containing cells were normally labelled in the same section
(Fig. 1g). All these control experiments attest to the specificity of our immunodetection of SUR1.

SUR1 localisation in islet cells SUR1 was detected in islets from the human (Fig. 2a,e), mouse (Fig. 2c) and rat (Fig. 2f) pancreas, and was apparently present in all endocrine cells. This was confirmed on consecutive sections of the same specimens by immunostaining of beta cells (brown) and non-beta cells (alpha+delta cells) (red) (Fig. 2b,d). In humans and rats, SUR1 staining intensity was lower in non-beta than beta cells (Fig. 2a,b for humans; for rats, see Fig. 4a,b). In the mouse, however, no obvious difference in SUR1 staining intensity was observed between beta and non-beta cells (Fig. 2c,d).

At higher magnification (Fig. 2e,f; human and rat, respectively), SUR1 was consistently found in the cyto-
Fig. 1 Specificity of SUR1 immunodetection. a In mouse hippocampus, SUR1 is localised in dentate gyrus granule cells $(g g)$ and in the pyramidal cells layer $(p c)$. The inset shows neurons of the gg area at high magnification. b SUR1 is not observed in mouse cardiomyocytes (arrows show intercalated discs; Hx). c In mouse pancreas, SUR1 is not present in vascular smooth muscle (arrow) but is distinctly observed in an islet of the same histological section (Hx). d SUR1 is present in peripheral nerve fibres $(n f)$ (human pancreatic parenchyma; $\mathrm{Hx}$ ). In the picture, the nerve is ending in a nerve plexus ( $n p)$. e, f Absence of SUR1 immunostaining in hippocampus area (e, low magnification; inset, high magnification) and in islets (f, arrow) from Sur ${ }^{-/}$mouse. g Insulin (red) and glucagon (green) immunofluorescent staining of the Sur $1^{-/}$islet in f. Bars $=100 \mu \mathrm{m}$

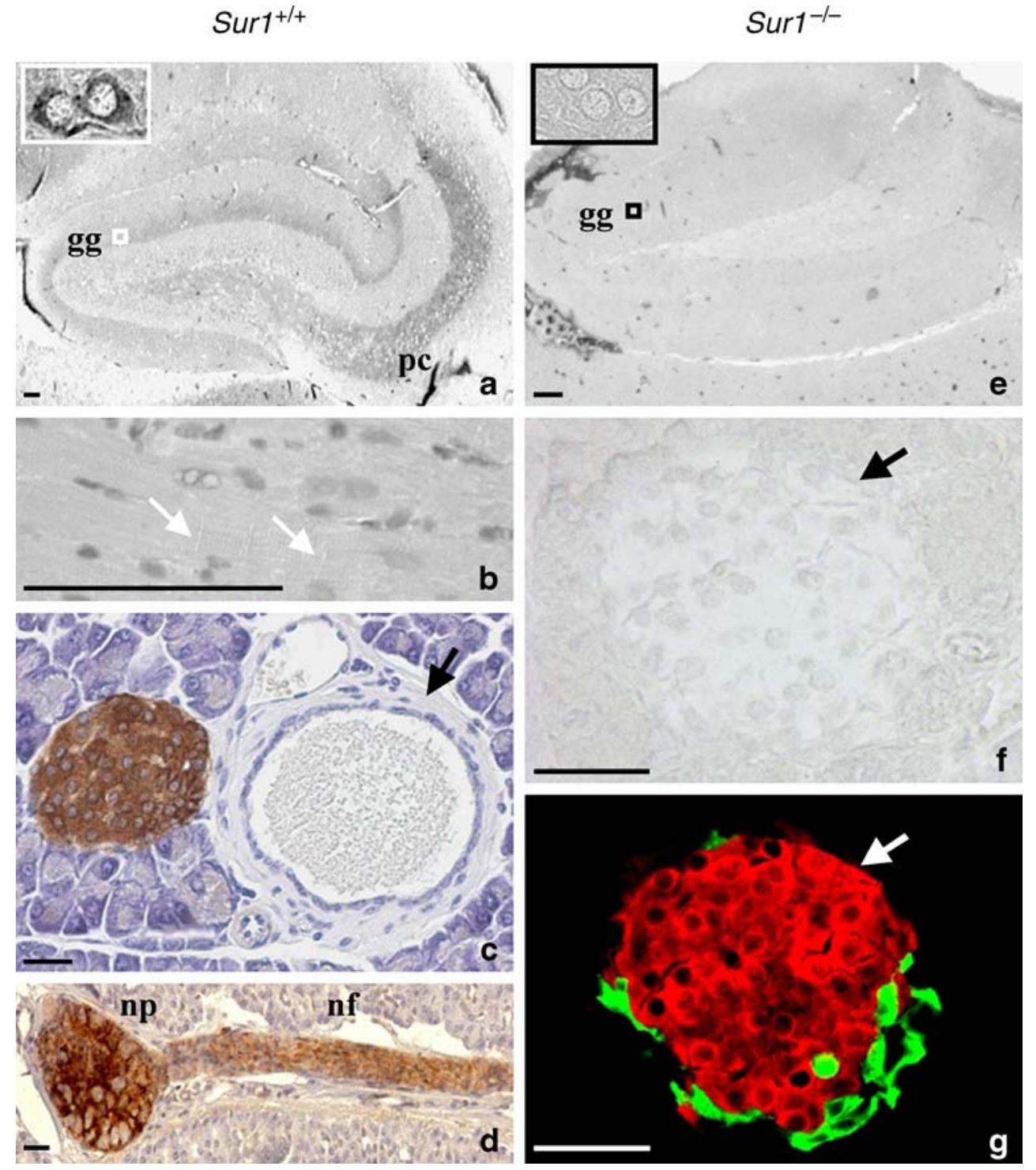


plasm of beta cells, with a variable staining intensity between cells, and sometimes concentrated at one pole of the cell (Fig. 2e,f, arrows). Labelling of the plasma membrane was also visible, particularly when the cytoplasmic staining was faint (Fig. 2e,f). The nuclear membrane of many (not all) beta cells was also stained.

Electron microscopy When the pancreas was processed for electron microscopy by classic methods including embedding in epoxy resin, the subcellular ultrastructure was well preserved and no obvious differences were noted between control and Sur $1^{-/-}$beta cells. Insulin granules showed their typical aspect, with a dense core and a clear halo (Fig. 3a,e). Unfortunately, this processing did not permit SUR1 immunodetection, which was only possible after short fixation and acrylic resin embedding, at the cost of poorer ultrastructural definition (Fig. 3b-d,f,g).

In control mouse islets, SUR1 was identified by the presence of gold particles in insulin (Fig. 3b,c) and glucagon (Fig. 3d) or somatostatin granules (not shown). No similar staining was observed in Sur $1^{-/}$islets (Fig. 3f,g). In control beta cells, the density of SUR1 gold particles was six times higher over insulin granules than the rest of the cytoplasm, but it was similar (ratio around 1 corresponding to background)
Fig. 2 SUR1 localisation in islet cells. SUR1 is localised in beta and non-beta cells of human (a) and mouse (c) islets as shown by the staining of insulin (in brown), somatostatin and glucagon (in red) in the next section of the same pancreas (b, $\mathbf{d}$ no counterstaining). SUR1 staining intensity varies between beta cells in human and rat islets (e and f, respectively). Cytoplasm, pole of the cell (arrows), plasma membrane and nuclear membrane are visibly stained in both species $(\mathrm{Hx})$. The working dilutions of anti-SUR1 antibody were $1 / 600$ in $\mathbf{a}, \mathbf{c}$ and $1 / 300$ in e, f. Bars $=50 \mu \mathrm{m}$
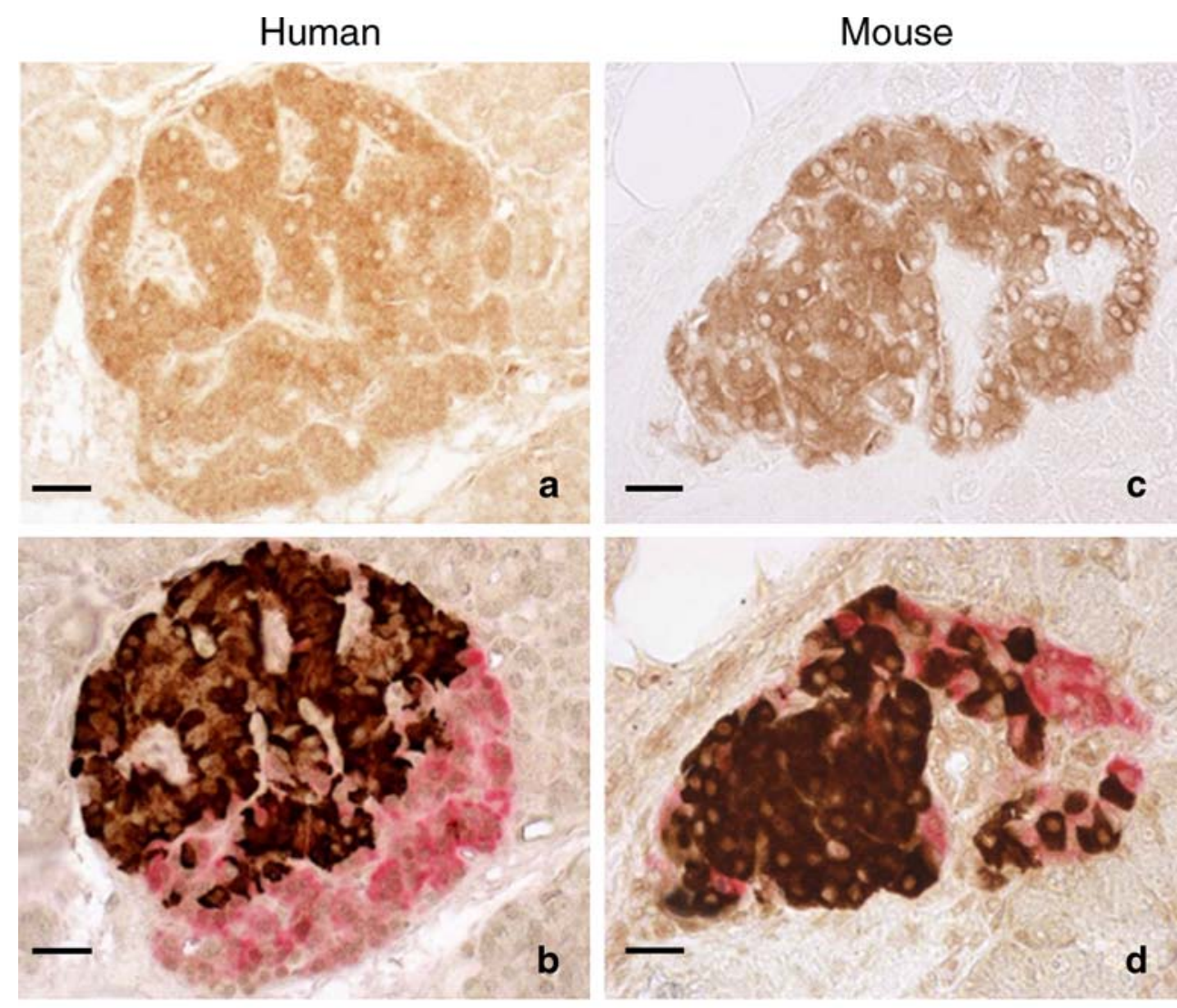

Human

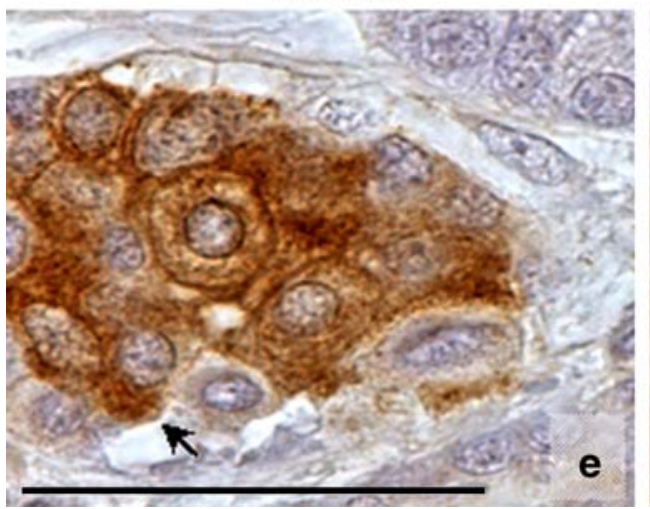

Rat

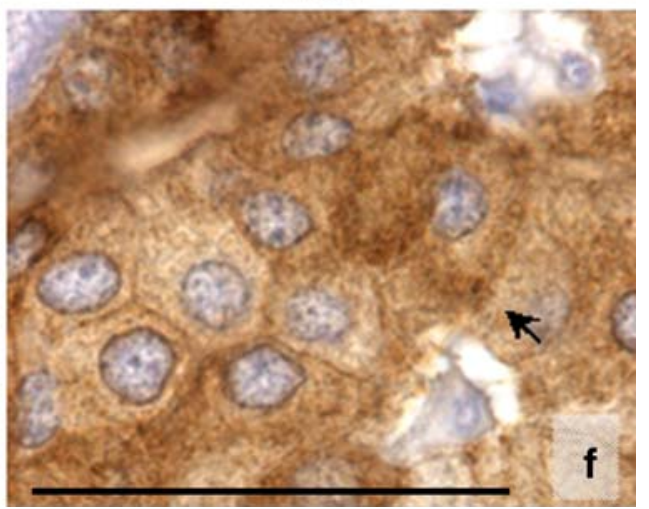


in Sur $^{-/-}$beta cells (Fig. 3h). SUR1 was also concentrated on insulin granules in the rat (see below in Fig. 5a,b).

SUR1 staining after beta cell degranulation Since the preceding results suggested that SUR1 was localised to insulin granules in addition to the plasma membrane, we studied the impact of beta cell degranulation. In islets from rats treated in vivo with glibenclamide the insulin immunostaining was markedly decreased (Fig. 4a,b). Strikingly,

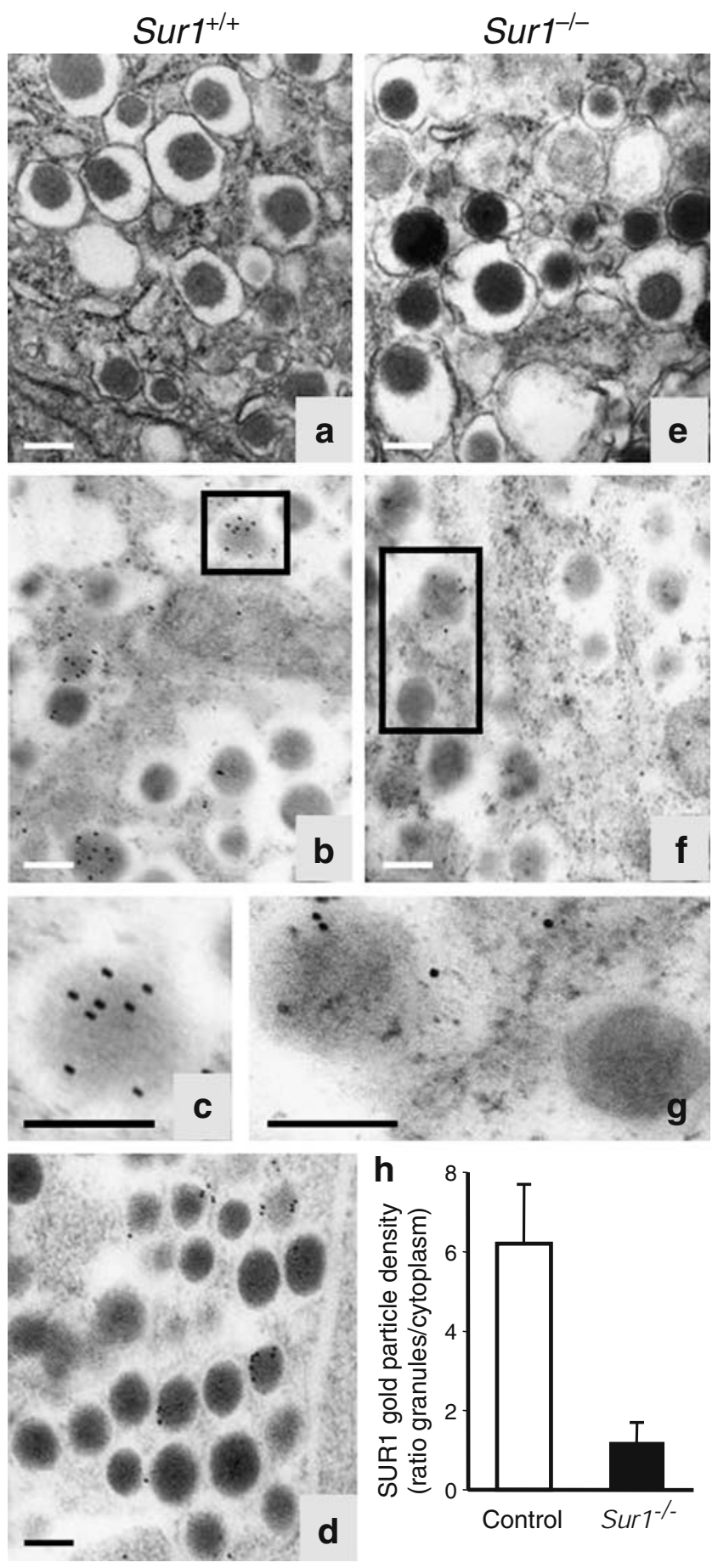

SUR1 staining was also decreased in beta cells but was not visibly affected in non-beta cells (Fig. 4d,e). The beta cell plasma membrane was clearly labelled by the anti-SUR1 antibody after degranulation (Fig. 4e, inset). The intensity of insulin and SUR1 staining was measured in the pancreas of five control and glibenclamide-treated rats (Fig. 4c,f). The SODs of insulin and SUR1 were similarly decreased by about $45 \%(p<0.001)$. The paired-correlation test was 0.83 between insulin and SUR1 contents $(p=0.005)$.

In comparison with control rats (Fig. 5a,d), the number of insulin granules was decreased by about $50 \%$ after glibenclamide treatment (Fig. 5b,e). This corresponds well with the decrease observed above by immunodensitometry. The immunodetection of either insulin or SUR1 further showed that the number of gold particles per insulin granule (identified by the dense core) was also decreased in the treated group (Fig. 5b,e, respectively). This visual impression was supported by the histograms representing the number of insulin or SUR1 gold particles per insulin granule (Fig. 5c,f, respectively). Strikingly, the percentage of insulin granules without insulin or SUR1 labelling was at least threefold higher after the treatment.

To ascertain that the difference in SUR1 labelling was not due to an interference caused by the presence of glibenclamide in beta cells, rather than to the degranulation, normal mouse islets were cultured overnight with $10 \mu \mathrm{mol} / \mathrm{l}$ glibenclamide and $2 \mu \mathrm{mol} / 1$ clonidine (to inhibit insulin secretion) [11] or clonidine alone. The intensity of SUR1 immunolabelling was similar in the two groups (not shown) indicating that the presence of glibenclamide did not interfere.

Glibenclamide binding In islet cell clusters from normal mice, glibenclamide-BODIPY-FL localised to punctate cytoplasmic structures, similar to secretory granules by their shape, size, number and location at the cell periphery (Fig. 6a). The intensity of the fluorescence was variable from cell to cell. The plasma membrane never showed any fluorescence labelling. When the recording time was

Fig. 3 Subcellular localisation of SUR1 in islet cells from normal and Sur $1^{-/}$mice. After conventional embedding (a, e), the morphological appearance of insulin granules is similar in normal and $\mathrm{Surl}^{-/}$mice. $\mathbf{b}, \mathbf{c}, \mathbf{d}, \mathbf{f}, \mathbf{g}$ The specific embedding required for SUR1 immunodetection explains the poorer morphological resolution. In normal mice, insulin (b and c, respectively at low and high magnification) and glucagon (d) granules are labelled by anti-SUR1 gold particles, with a low background outside the granules. In contrast, no specific staining is localised to insulin granules in $\operatorname{Surl}^{-/-}$mice (f and $\mathbf{g}$, respectively at low and high magnification). h Ratio of gold particle density over granules/cytoplasm. It is about six in beta cells from normal mice and close to one in beta cells from Sur $1^{-/}$mice $(p<0.001)$. Five hundred and fifty-two insulin granules from five beta cells (two normal mice) and 850 insulin granules from seven beta cells (two Surl ${ }^{-/}$mice) were counted. Values are means \pm SD. Bars $=125 \mathrm{~nm}$ 
increased from 400 to $3,600 \mathrm{~ms}$, the fluorescent signal was diffusely intense over the whole cytoplasm (Fig. 6b). The specificity of the procedure was checked by competitive displacement of $10 \mathrm{nmol} / 1$ glibenclamide-BODIPY-FL with $4 \mu \mathrm{mol} / \mathrm{l}$ unlabelled glibenclamide, which resulted in a marked decrease of the fluorescent signal (data not shown).

After incubation with BODIPY-FL dye alone, as a negative control, a weak fluorescent signal was detected by the camera after the same period of recording (400 ms) as that used for observation of the preparations incubated with glibenclamide-BODIPY-FL (Fig. 6c). However, when
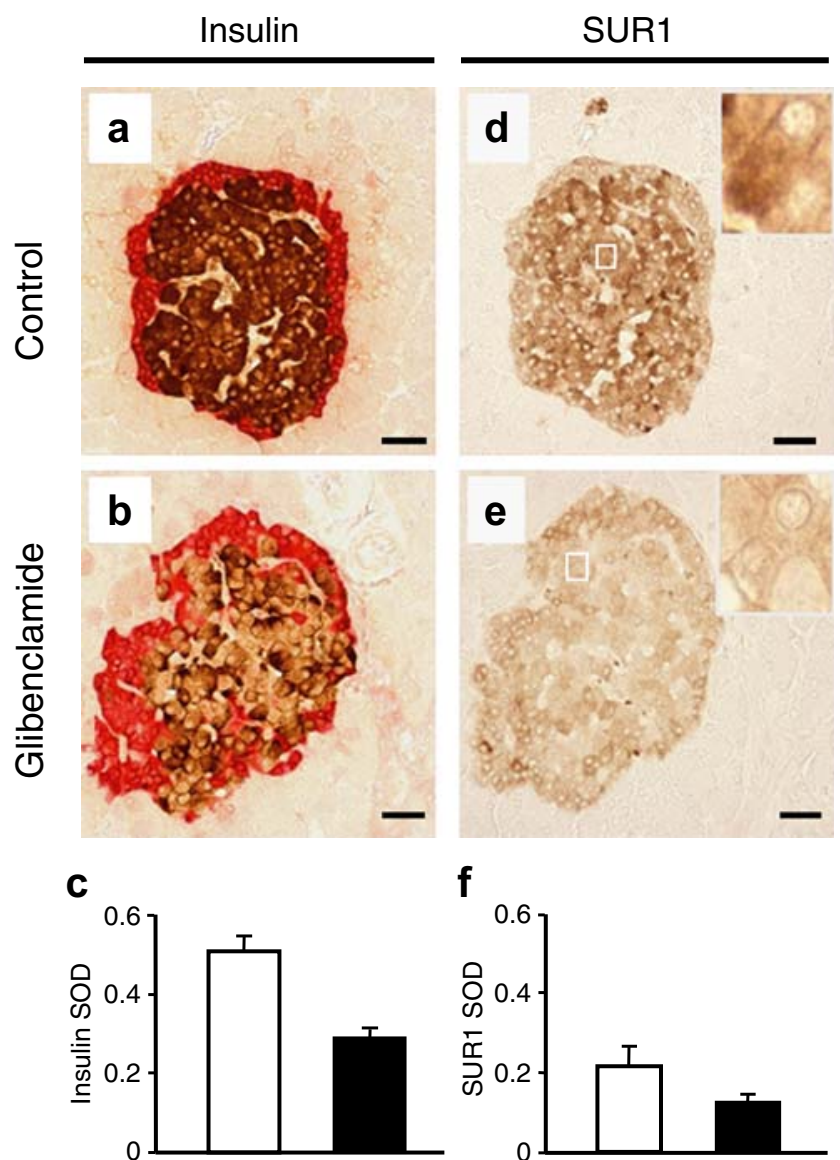

\section{f}

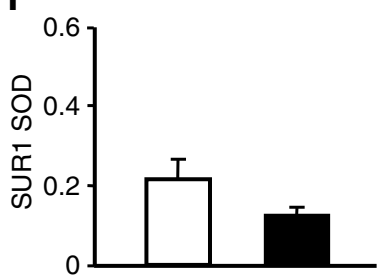

Fig. 4 Quantification of insulin and SUR1 immunostaining intensities in islets from control and glibenclamide-treated rats. a, b Somatostatin and glucagon cells ( $r e d$ ) surround central insulin cells (brown). b After glibenclamide treatment, insulin immunostaining is markedly decreased (brown) as confirmed by the immunodensitometric measurements (c). d SUR1 staining is present in all endocrine cells of the islets, with a higher intensity in beta than non-beta cells. The staining is particularly prominent in the secretory pole area (inset). e After degranulation, SUR1 staining intensity is also decreased in beta cells without modification in non-beta cells. A distinct membrane staining is visible (inset). f Quantification of SUR1 immunostaining intensity. A total of 88 and 112 control islets (open columns) and 119 and 71 glibenclamide-treated islets (closed columns) were examined for insulin and SUR1 staining, respectively. SOD for both was significantly decreased after degranulation $(p<0.001)$. Bars $=50 \mu \mathrm{m}$ the recording time was increased to $3,600 \mathrm{~ms}$, fluorescent cytoplasmic dots larger than endocrine granules and fewer in number were detected (Fig. 6d). Clusters of islet cells from $\mathrm{Surl}^{-1-}$ mice were also incubated either with glibenclamide-BODIPY-FL (Fig. 6e,f) or with BODIPYFL dye alone (Fig. 6g,h). In these islets lacking SUR1, the two probes gave a similar labelling, comparable in shape and intensity to that of BODIPY-FL dye alone in normal clusters (compare Fig. 6e-h with Fig. 6c,d). No specific labelling of glibenclamide-BODIPY-FL was thus detected in the absence of SUR1.
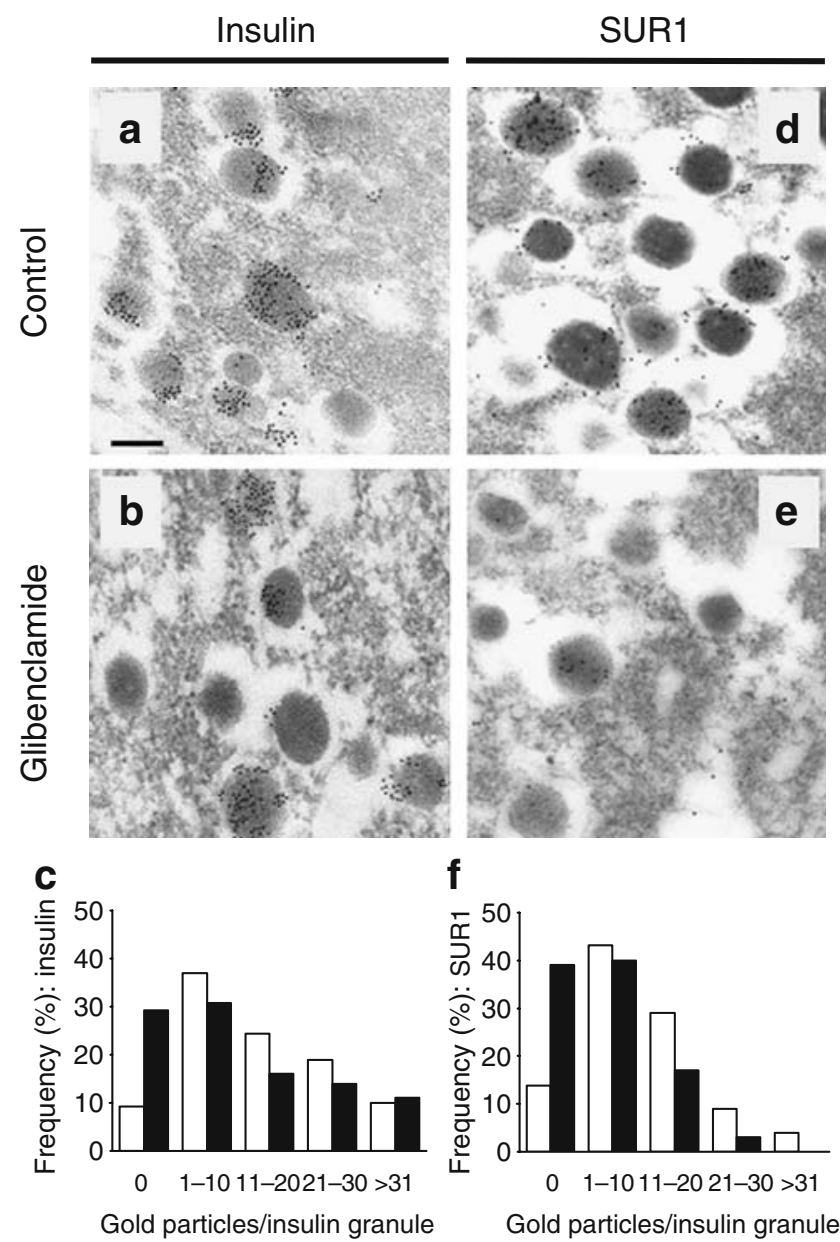

Fig. 5 Quantification of insulin and SUR1 gold particles in beta cells from control and glibenclamide-treated rats. Insulin $(\mathbf{a}, \mathbf{b})$ and SUR1 $(\mathbf{d}, \mathbf{e})$ visualised by the immunogold particles in insulin granules from control (a, d) and glibenclamide-treated rats (b, e). Distribution histograms of the insulin (c) and SUR1 (f) number of gold particles per insulin granule. As no membranes were visible, insulin granules were identified by the presence of a spherical dense core surrounded by a clear halo. Gold particles localised in empty vesicles were not counted. Insulin and SUR1 histograms were determined, respectively, from 524 or 180 (control, open columns) and 368 or 91 (glibenclamidetreated, closed columns) insulin granules, in at least two beta cells from two rats per group. Bar $=120 \mathrm{~nm}$ 


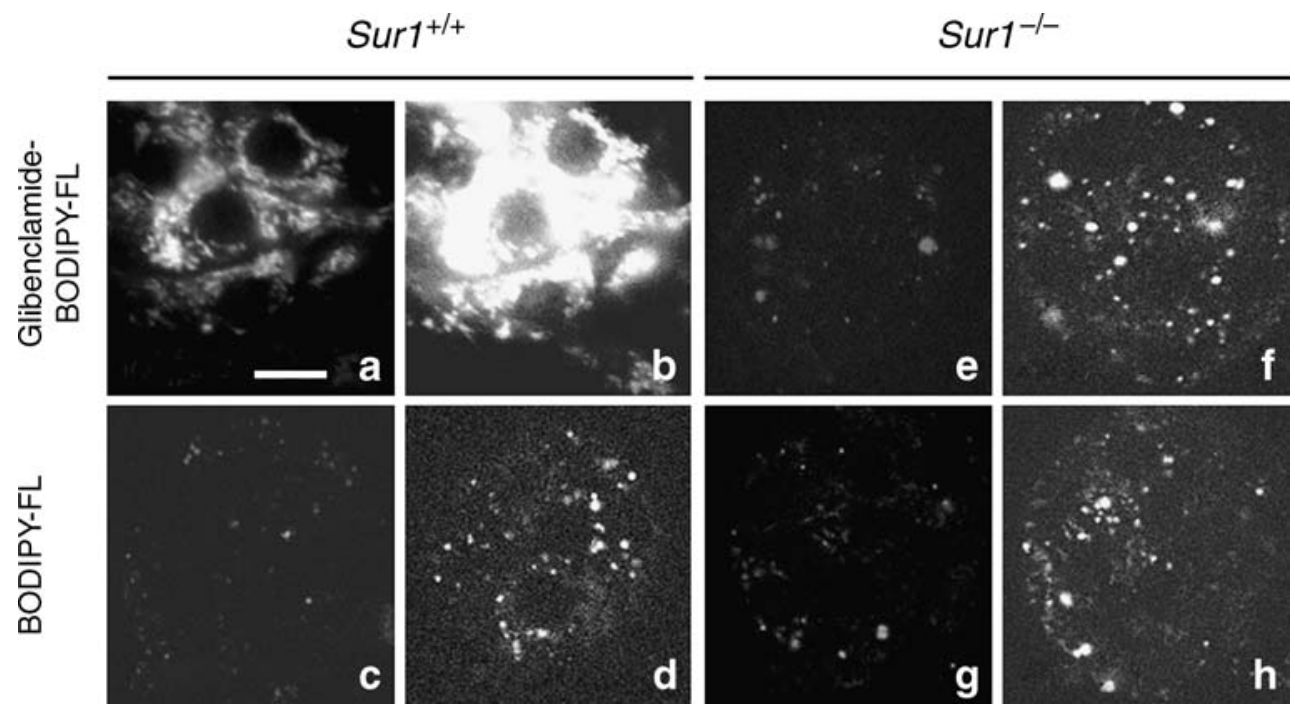

Fig. 6 Comparison of glibenclamide-BODIPY-FL and BODIPY-FL dye binding to islet cell clusters from normal and $\mathrm{Surl}^{-/}$mice. a Control clusters incubated with glibenclamide-BODIPY-FL. Pictures taken after $400 \mathrm{~ms}$ of recording time. The probe is localised to punctate structures reminiscent of secretory granules. b When the recording time was increased to $3,600 \mathrm{~ms}$, the fluorescence was saturated giving an intense signal over the whole cytoplasm. c, d Control clusters incubated with BODIPY-FL dye alone; recording

\section{Discussion}

Immunohistochemical techniques can be misleading when the specificity of the antibody has not been strictly assessed. SUR1 is a member of the ATP-binding cassette transporter superfamily, whose members display high homology in their sequence. Although the specificity of our SUR1 antibody, directed against nucleotide-binding domain 1, had been characterised by other methods [4], we validated its use in immunohistochemistry by testing its reactivity in tissues whose SUR type was established by molecular and pharmacological approaches $[35,36]$.

In situ hybridisation studies have identified brain areas abundantly expressing SUR1 in the hippocampus region. Their immunolabelling served as a positive control of our technique. Our detection of SUR1 in nerve fibres of the pancreas extends a previous identification of $\mathrm{K}_{\text {ATP }}$ channels in glucoresponsive neurons of the enteric nervous system [37]. Whether the presence of these metabolic sensors in intrapancreatic nerves has implications for the neural control of islet hormone secretion is presently unknown. The absence of SUR1 immunostaining in cardiac and vascular muscle cells, which contain SUR2A and SUR2B, respectively $[6,8,35,36]$, excludes possible cross-reactions with other SUR isoforms. Finally, the decisive proof of the specificity of our immunodetections was provided by the absence of labelling in islets and other tissues from Surl ${ }^{-/}$ mice. time of 400 and $3,600 \mathrm{~ms}$, respectively. The staining intensity is faint when the recording time is the same as in a (c). A distinct signal is detected after longer recording time (d). e-h Surl ${ }^{-/-}$clusters incubated with glibenclamide-BODIPY-FL $(\mathbf{e}, \mathbf{f})$ or BODIPY-FL dye alone $(\mathbf{g}, \mathbf{h})$; recording times of $400(\mathbf{e}, \mathbf{g})$ and 3,600 $\mathrm{ms}(\mathbf{f}, \mathbf{h})$. The signal was similar with both probes and similar to that produced by BODIPY-FL in control islets (d), meaning that this labelling is nonspecific. Bar $=10 \mu \mathrm{m}$

In beta cells, the major immunostaining of SUR1 was cytoplasmic, as in two previous studies $[15,16]$. The punctate aspect of this labelling by conventional microscopy and its occasional concentration at one (secretory) [38] pole of the cell were highly suggestive of the presence of SUR1 in insulin-containing granules, in agreement with recent proposals $[16,22]$. This location may explain the differences in the intensity of SUR1 labelling between beta cells. Thus, within an islet, insulin immunostaining is heterogeneous under both basal and stimulatory conditions $[31,39,40]$. Our conclusion is directly supported by ultrastructural investigations (immunogold technique) showing a concentration of SUR1 over insulin granules. A further proof was provided by a functional study based on the evidence that, under controlled staining conditions, the labelling intensity of an antigen immunodetected on histological sections is correlated with its actual tissue content [31]. Beta cell degranulation, by strong in vivo stimulation of insulin secretion with glibenclamide administration to rats, decreased the SOD of immunolabelled insulin and SUR1 to a similar average extent of $45 \%$, whereas no similar decrease in SUR1 occurred in non-beta cells. A strong correlation has been observed between cellular insulin content and number of ${ }^{3} \mathrm{H}$-labelled glibenclamidebinding sites in different beta cell sources differing markedly in their degree of granulation [18].

From functional studies it is evident that beta cell $\mathrm{K}_{\mathrm{ATP}}$ channels, hence SUR1, are present in the plasma mem- 
brane. Our results provide the first visualisation of SUR1 at that level in human and rodent endocrine pancreas. This localisation could be demonstrated in cells whose cytoplasmic staining was low, either spontaneously (variations between beta cells) or after imposed degranulation with glibenclamide, because of an increased contrast between the plasma membrane and the cytoplasm. Like others $[16$, 19, 20], we found the glibenclamide-BODIPY technique inadequate to localise SUR1 in the plasma membrane. In this respect our ultrastructural studies were also disappointing because of the relatively poor preservation of membranes by the technical conditions imposed by SUR1 immunodetection at the electron microscopic level. The peptide was only detected at the sites of high concentration, the endocrine granules. All this reinforces the conclusions of binding or autoradiographic studies indicating that only about $10 \%$ of glibenclamide-binding sites are associated with the plasma membrane $[18,21]$. When the cytoplasmic background was low, SUR1 was also identified in the nuclear membrane (not within the nucleus) of islet cells from the three studied species. This localisation is in agreement with one study [23], but contrasts with another one [16], both being based on glibenclamide-BODIPY binding in mouse islets.

Our study also unequivocally shows that SUR1 is present in non-beta cells of mouse, rat and human islets, with a predominant intracellular localisation, particularly in glucagon and somatostatin granules. These results extend the previous immunodetection of SUR1 in all endocrine cells of rat islets [15]. Comparison of SUR1 staining intensity in beta and non-beta cells revealed species differences. In rat islets, the rim of alpha and delta cells exhibited a fainter staining than did the core of beta cells. This difference is at odds with the suggestion, based on in situ hybridisation, that SUR1 expression is stronger in alpha than beta cells of the rat [28]. However, it agrees with the electron microscopic observation that the accumulation of radioactive glibenclamide was about twofold lower in non-beta than beta cells [21]. In contrast to rats and humans, SUR1 staining intensity was similar or perhaps even higher in non-beta than beta cells in mice. The significance of these species differences is not known, but it is noteworthy that current views of alpha cell stimulussecretion coupling ascribe a variable role to $\mathrm{K}_{\mathrm{ATP}}$ channels in the regulation of glucagon secretion by glucose in different species [41].

The methods using radioactive [21] or fluorescent [16, 19] glibenclamide to visualise sulfonylurea-binding sites in islet cells did not identify the molecular nature of these sites and are not without pitfalls. We observed staining of islets from Surl $^{-/}$mice with glibenclamide-BODIPY-FL, but this staining in the absence of SUR1 is unlikely to identify a second specific binding site of glibenclamide (such as the
gSUR protein) since it was similar to that observed with BODIPY-FL dye alone in both $\mathrm{Surl}^{-/}$or control islets. This non-specific labelling in control islets was far less than the $80 \%$ of total labelling measured in RINm5F cells [20]. We attribute this difference to the higher density of insulin granules in normal beta cells compared with the cell line [42], hence to a greater proportion of specific binding sites.

Overall, our data suggest that the gSUR protein is not closely related to SUR1 and show that it is not detected by glibenclamide-BODIPY-FL in intact cell clusters. It is unclear whether this lack of detection is due to low amounts or low affinity of gSUR for glibenclamide. The latter possibility has previously been suggested [27].

The functional role of intracellular SUR1 cannot be established by our morphological approach but a number of possibilities can be envisaged. Because Kir6.2 has also been localised to insulin granules by light or electron microscopy $[16,22]$, it is plausible that the two proteins are associated and form $\mathrm{K}_{\mathrm{ATP}}$ channels. A first possibility is that the channels use secretory granules to translocate to the plasma membrane. However, whatever the technique of visualisation used, we were unable to detect an increase in SUR1 staining in the plasma membrane after stimulation of insulin granule exocytosis. Moreover, this unusual mechanism would not readily be compatible with the apparently much shorter half-life of SUR1 [43, 44] than of insulin stores in beta cells. Alternatively, $\mathrm{K}_{\mathrm{ATP}}$ channels could serve a specific function in the granules. A role in granular maturation is unlikely because the ultrastructural aspect of insulin granules is normal in $\mathrm{Surl}^{-/-}$beta cells. It has been suggested that the control of granular $\mathrm{K}_{\mathrm{ATP}}$ channels by ATP/ADP is important for the amplification of secretion during the second phase of glucose stimulation [16]. However, this attractive hypothesis was not supported by our demonstration that the amplifying pathway functions normally in $\mathrm{Surl}^{-/-}$beta cells lacking $\mathrm{K}_{\mathrm{ATP}}$ channels [45]. Another proposal is that granular SUR1 regulates a $\mathrm{Cl}^{-}$ channel involved in granular acidification and represents an intracellular target for hypoglycaemic sulfonylureas [27, 46]. However, we have previously challenged the view that an intracellular site of action is important for the insulinreleasing action of sulfonylureas [47]. Moreover, the effects of intracellularly applied sulfonylureas on exocytosis, as measured by capacitance changes, persist in $\mathrm{Surl}^{-/}$beta cells [48], while extracellularly applied sulfonylureas are inactive $[12,45,48]$. Finally, the acute acidification of insulin granules produced by glucose does not require SUR1 [49]. All these observations suggest that a protein other than SUR1 is involved. Intriguingly, this protein is not detectable by the glibenclamide-BODIPY technique.

In summary, our study immunolocalised SUR1 in alpha, beta and delta cells of human, mouse and rat islets, and for the first time visualised it in the plasma membrane. We also 
show that SUR1 is abundant in endocrine granules where its function remains to be established. Finally, application of the glibenclamide-BODIPY-FL technique to normal and Sur $^{-/-}$islets did not identify specific sulfonylurea-binding sites other than SUR1.

Acknowledgements We thank R. M. Goebbels and A. Salliez for their expert technical assistance, S. Roelandts (LUXOPTICS, Beaumont, Belgium) for the loan of both the ApoTome system and the Zeiss AxioImager Z1 Motorised Microscope and J. Bryan (Houston, TX, USA) for providing the Surl ${ }^{-/}$mice. This work was supported by grants 3.4594.99 (J. Rahier) and 1.5.216.04 (C. Sempoux) from the Fonds National de la Recherche Scientifique, Brussels, and by grant ARC 05/ 10-328 from the Direction de la Recherche Scientifique de la Communauté Française de Belgique. P. Stiernet is Research Assistant of the Fonds National de la Recherche Scientifique, Brussels, Belgium.

Duality of interest The authors declare that there is no duality of interest associated with this manuscript.

\section{References}

1. Clement JP, Kunjilwar K, Gonzalez G et al (1997) Association and stoichiometry of $\mathrm{K}_{\text {ATP }}$ channel subunits. Neuron 18:827-838

2. Shyng S, Nichols CG (1997) Octameric stoichiometry of the $K_{\text {ATP }}$ channel complex. J Gen Physiol 110:655-664

3. Inagaki N, Gonoi T, Seino S (1997) Subunit stoichiometry of the pancreatic beta-cell ATP-sensitive $\mathrm{K}^{+}$channel. FEBS Lett 409:232-236

4. Mikhailov MV, Mikhailova EA, Ashcroft SJH (2000) Investigation of the molecular assembly of B-cell $\mathrm{K}_{\text {ATP }}$ channels. FEBS Lett 482:59-64

5. Ashcroft FM, Rorsman P (1989) Electrophysiology of the pancreatic beta-cell. Prog Biophys Mol Biol 54:87-143

6. Aguilar-Bryan L, Bryan J (1999) Molecular biology of adenosine triphosphate-sensitive potassium channels. Endocr Rev 20:101-135

7. Henquin JC (2000) Triggering and amplifying pathways of regulation of insulin secretion by glucose. Diabetes 49:1751-1760

8. Seino S, Miki T (2003) Physiological and pathophysiological roles of ATP-sensitive $\mathrm{K}^{+}$channels. Prog Biophys Mol Biol 81:133-176

9. Aizawa T, Sato Y, Komatsu M (2002) Importance of non-ionic signals for glucose-induced biphasic insulin secretion. Diabetes 51 (Suppl 1):S96-S98

10. Straub SG, Sharp GW (2002) Glucose-stimulated signaling pathways in biphasic insulin secretion. Diabetes Metab Res Rev $18: 451-463$

11. Henquin JC, Ravier MA, Nenquin M, Jonas JC, Gilon P (2003) Hierarchy of the beta-cell signals controlling insulin secretion. Eur J Clin Invest 33:742-750

12. Henquin JC (2004) Pathways in $\beta$-cell stimulus-secretion coupling as targets for therapeutic insulin secretagogues. Diabetes 53 (Suppl 3):S48-S58

13. Gribble FM, Reimann F (2003) Sulphonylurea action revisited: the post-cloning era. Diabetologia 46:875-891

14. Bryan J, Vila-Carriles WH, Zhao G, Babenko AP, Aguilar-Bryan L (2004) Toward linking structure with function in ATP-sensitive $\mathrm{K}^{+}$channels. Diabetes 53(Suppl 3):S104-S112
15. Suzuki M, Fujikura K, Inagaki N, Seino S, Takata K (1999) Immuno-localisation of sulphonylurea receptor 1 in rat pancreas. Diabetologia 42:1204-1211

16. Geng X, Lehong L, Watkins S, Robbins P, Drain P (2003) The insulin secretory granule is the major site of $\mathrm{K}_{\mathrm{ATP}}$ channels of the endocrine pancreas. Diabetes 52:767-776

17. Hellman B, Sehlin J, Täljedal IB (1984) Glibenclamide is exceptional among hypoglycaemic sulphonylureas in accumulating progressively in B-cell-rich pancreatic islets. Acta Endocrinol (Copenh) 105:385-390

18. Ozanne SE, Guest PC, Hutton JC, Hales CN (1995) Intracellular localization and molecular heterogeneity of the sulphonylurea receptor in insulin-secreting cells. Diabetologia 38:277-282

19. Quesada I, Nadal A, Soria B (1999) Different effects of tolbutamide and diazoxide in alpha-, beta- and delta-cells within intact islets of Langerhans. Diabetes 48:2390-2397

20. Zünkler B, Wos-Maganga M, Panten U (2004) Fluorescent microscopy studies with a fluorescent glibenclamide derivative, a high-affinity blocker of pancreatic B-cell ATP-sensitive $\mathrm{K}^{+}$ currents. Biochem Pharmacol 67:1437-1444

21. Carpentier JL, Sawano F, Ravazzola M, Malaisse WJ (1986) Internalization of $3 \mathrm{H}$-glibenclamide in pancreatic islet cells. Diabetologia 29:259-261

22. Varadi A, Grant A, McCormack M et al (2006) Intracellular ATP-sensitive $\mathrm{K}(+)$ channels in mouse pancreatic beta cells: against a role in organelle cation homeostasis. Diabetologia 49:1567-1577

23. Quesada I, Rovira J, Martin F, Roche E, Nadal A, Soria B (2002) Nuclear KATP channels trigger nuclear $\mathrm{Ca}^{2+}$ transients that modulate nuclear function. Proc Natl Acad Sci USA 99:95449549

24. Yang SN, Dekki NF, Yu L et al (2005) A novel regulated exocytotic pathway mediates glucose-induced $\mathrm{K}_{\mathrm{ATP}}$ channel recruitment to the $\beta$-cell plasma membrane. Diabetologia 48 (Suppl 1):A67

25. Kramer W, Muller G, Geisen K (1996) Characterization of the molecular mode of action of the sulfonylurea, glimepiride, at betacells. Horm Metab Res 28:464-468

26. Barg S, Renström E, Berggren PO et al (1999) The stimulatory action of tolbutamide on $\mathrm{Ca}^{2+}$-dependent exocytosis in pancreatic $\beta$ cells is mediated by a $65-\mathrm{kDa}$ mdr-like P-glycoprotein. Proc Natl Acad Sci USA 96:5539-5544

27. Renström E, Barg S, Thevenod F, Rorsman P (2002) Sulfonylureamediated stimulation of insulin exocytosis via an ATP-sensitive $\mathrm{K}^{+}$ channel-independent action. Diabetes 51(Suppl 1):S33-S36 (Review)

28. Bokvist K, Olsen HL, Hoy M et al (1999) Characterisation of sulphonylurea and ATP-regulated $\mathrm{K}^{+}$channels in rat pancreatic Acells. Pflugers Arch 438:428-436

29. Gromada J, Ma X, Hoy M et al (2004) ATP-sensitive $\mathrm{K}^{+}$channeldependent regulation of glucagon release and electrical activity by glucose in wild-type and SUR1-/- mouse $\alpha$-cells. Diabetes 53 (Supp 3):S181-S189

30. Seghers V, Nakazaki M, DeMayo F, Aguilar-Bryan L, Bryan J (2000) SUR1 knockout mice. A model for $\mathrm{K}_{\mathrm{ATP}}$ channelindependent regulation of insulin secretion. J Biol Chem 275:9270-9277

31. Rahier J, Stevens M, de Menten Y, Henquin JC (1989) Determination of antigen concentration in tissue sections by immunodensitometry. Lab Invest 61:357-363

32. Jonkers FC, Jonas JC, Gilon P, Henquin JC (1999) Influence of cell number on the characteristics and synchrony of $\mathrm{Ca}^{2+}$ 
oscillations in clusters of mouse pancreatic islet cells. J Physiol 520:839-849

33. Karschin C, Ecke C, Ashcroft FM, Karschin A (1997) Overlapping distribution of $\mathrm{K}_{\mathrm{ATP}}$ channel-forming Kir6.2 subunit and the sulfonylurea receptor SUR1 in rodent brain. FEBS Lett 401:59-64

34. Hernandez-Sanchez C, Basile AS, Fedorova I et al (2001) Mice transgenically overexpressing sulfonylurea receptor 1 in forebrain resist seizure induction and excitotoxic neuron death. Proc Natl Acad Sci USA 98:3549-3554

35. Moreau C, Jacquet H, Prost AL, D'hahan N, Vivaudou M (2000) The molecular basis of the specificity of action of K(ATP) openers. EMBO J 19:6644-6651

36. Gribble FM, Reimann F (2002) Pharmacological modulation of K (ATP) channels. Biochem Soc Trans 30:333-339

37. Liu MT, Seino S, Kirchgessner AL (1999) Identification and characterization of glucoresponsive neurons in the enteric nervous system. J Neurosci 19:10305-10317

38. Bonner-Weir S (1988) Morphological evidence for pancreatic polarity of $\beta$-cell within islets of Langerhans. Diabetes 37:616-621

39. Stefan Y, Meda P, Neufeld M, Orci L (1987) Stimulation of insulin secretion reveals heterogeneity of pancreatic B cells in vivo. J Clin Invest 80:175-183

40. Jörns A (1994) Immunocytochemical and ultrastructural heterogeneities of normal and glibenclamide stimulated pancreatic beta cells in the rat. Virchows Arch 425:305-313

41. Kanno T, Gopel SO, Rorsman P, Wakui M (2002) Cellular function in multicellular system for hormone-secretion: electrophysiological aspect of studies on $\alpha-, \beta$ - and $\delta$-cells of the pancreatic islet. Neurosci Res 42:79-90
42. Persaud SJ (1999) Pancreatic $\beta$-cell lines: their roles in $\beta$-cell research and diabetes therapy. In: Bittar EE, Howell SL (eds) Advances in molecular and cell biology, vol 29. JAI Press, Stanford, CT, pp 21-46

43. Crane A, Aguilar-Bryan L (2004) Assembly, maturation, and turnover of $\mathrm{K}_{\text {ATP }}$ channel subunits. J Biol Chem 279:9080-9090

44. Yan FF, Lin CW, Cartier EA, Shyng SL (2005) Role of ubiquitinproteasome degradation pathway in biogenesis efficiency of betacell ATP-sensitive potassium channels. Am J Physiol Cell Physiol 289:C1351-C1359

45. Nenquin M, Szollosi A, Aguilar-Bryan L, Bryan J, Henquin JC (2004) Both triggering and amplifying pathways contribute to fuel-induced insulin secretion in the absence of sulfonylurea receptor-1 in pancreatic $\beta$-cells. J Biol Chem 279:32316-32324

46. Barg S, Eliasson L, Renström E, Rorsman P (2002) A subset of 50 secretory granules in close contact with L-type $\mathrm{Ca}^{2+}$ channels accounts for first phase insulin secretion in mouse $\beta$ cells. Diabetes 51(Suppl 1):S74-S82

47. Mariot P, Gilon P, Nenquin M, Henquin JC (1998) Tolbutamide and diazoxide influence insulin secretion by changing the concentration but not the action of cytoplasmic $\mathrm{Ca}^{2+}$ in $\beta$-cells. Diabetes 47:365-373

48. Eliasson L, Ma X, Renström E et al (2003) SUR1 regulates PKAindependent cAMP-induced granule priming in mouse pancreatic $\beta$-cells. J Gen Physiol 121:181-197

49. Stiernet P, Guiot Y, Gilon P, Henquin JC (2006) Glucose acutely decreases $\mathrm{pH}$ of secretory granules in mouse pancreatic islets. Mechanisms and influence on insulin secretion. J Biol Chem 281:22142-22151 